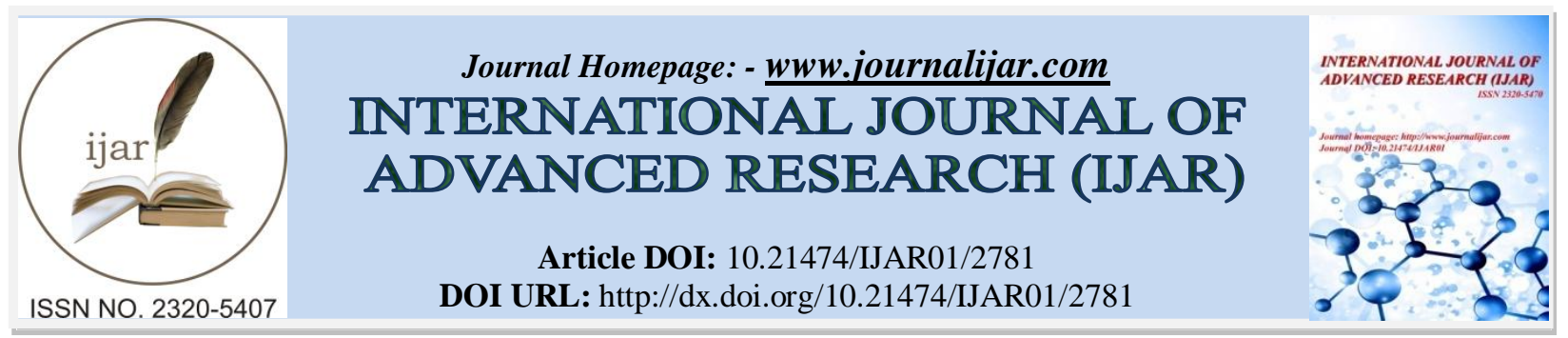

RESEARCH ARTICLE

\title{
KISSING NEVUS WITH OCULAR MELANOSIS: A CASE REPORT IN HAIL REGION, SAUDI ARABIA.
}

Rakan M Algorinees, Ibrahim G Alreshidi, Reem S AlShammari and Jluwi S Almasaud. College of Medicine, University of Hail, Kingdom of Saudi Arabia (KSA).

\section{Manuscript Info \\ Manuscript History \\ Received: 15 November 2016 \\ Final Accepted: 17 December 2016 \\ Published: January 2017}

Abstract

Copy Right, IJAR, 2016,. All rights reserved.

\section{Introduction:-}

Kissing nevus (also known as "congenital melanosis bulbi" or "nevus fuscoceruleus ophthamomaxillaris") is a congenital nevus that affects parts of the upper and lower eyelid and owing to its name, because when the eyelids during closure approach and touch (kiss) each other [1]. The entire eye as conjunctiva, sclera, cornea, retina and optic disc could be involved in this disease. The malignant transformation was described in many cases especially in oral, uveal and leptomeningeal melanosis[2][3]. Unilateral presentation is classically seen in most cases. It is very frequent in Japanese descent and rarely in others descents [4]. This is the first report in northern region of Saudi Arabia.

\section{Case report:-}

A 3 months old boy presented to the ophthalmology clinic in King Khalid Hospital, Hail, Saudi Arabia with a black discoloration of the left eyelids since birth, his family and medical histories were unremarkable.

An Ophthalmic examination, the patient is fixing and following the objects normally, pupils equal, round and reactive to light and accommodation, Intraocular pressure is $14 \mathrm{mmHg}$ on both eyes. On inspection, the left eye showed dark pigmentation covering the lateral third of left upper and lower lids, along with dark scleral pigmentation [Figure 1].

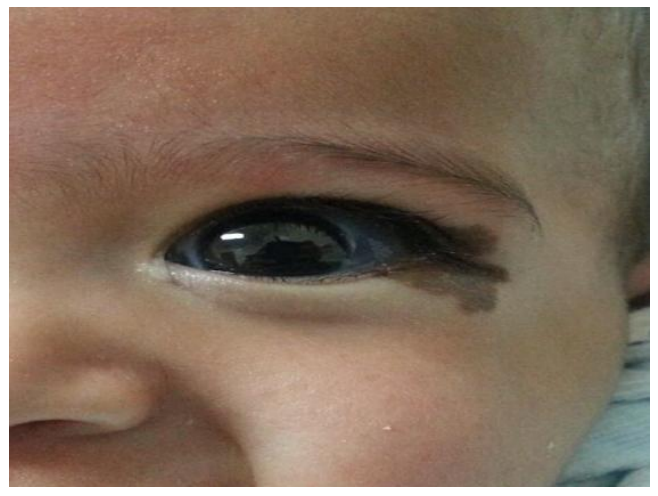

Corresponding Author:- Rakan M Algorinees.

Address:- College of Medicine, University of Hail, Kingdom of Saudi Arabia (KSA). 
Figure. 1:-The iris is normal in both eyes. Dilated fundus examination showed dark choroid in left eye. The cycloplegic refraction is not significant bilaterally. The patient is given follow up every 6 months for possible complication.

\section{Result and discussion:-}

Congenital nevus occurs in about $1 \%$ of all newborns [11]. It is more common in asian population comparing to other ethnic groups. The nevus of Ota occurs due to migration of melanocytes during the fusion of upper and lower eyelids before splitting of both eye lids, then after the separation of upper and lower eye lids the touch (kiss) each other during eye closure giving us "kissing" or split nevus [12].

Mostly it is a benign unilateral melanocytosis, also $80 \%$ of the patients were females [5] and 48\% of patients developed a nevus of Ota at or after birth compared to $11 \%$ between 1 and 10 years of age and 36\% at puberty [6]. In our patient who is 3 months old, came with unilateral black discoloration of upper and lower eyelids, the sclera discoloration and dark choroid on fundoscopic examination furthermore the vision and ocular function was intact. In Caucasian decent there is an association between ota nevus and uveal melanoma well documented. It is valued of 1 in 400 patients with ota nevus they will developed uveal melanoma later in their life, comparison to one of 13,000 in the general population [7]. It is thought that in fair skin patients the prevalence of melanomas is higher due to lacking of the protective effect of darker pigmentation [8]. Even though the glaucoma is frequently associated with ota nevus in Black descent but we should consider it [9][10]. For that they need at least 6 months follow up to predict any of this well known complications.

\section{Conclusion:-}

To our knowledge it is the first report in Northern Region of Saudi Arabia, which highlight the attention of this rare disease in our area. We recommend lifelong follow up (every 6 moths) of diagnosed cases of ota nevus to catch any melanoma changes or development of glaucoma.

\section{References:-}

1. McDonnell PJ, Mayou BJ. Congenital divided naevus of the eyelids.Br J Ophthalmol 1988;72:198-201.

2. M. Balmaceda, M. R. Fetell, J. L. O’Brien, and E. H. Housepian, "Nevus of Ota and leptomeningeal melanocytic lesions," Neurology, vol. 43, no. 2, pp. 381-386, 1993.

3. V. Rahimi-Movaghar and M. Karimi, "Meningeal melanocy- toma of the brain and oculodermal melanocytosis (nevus of Ota): case report and literature review," Surgical Neurology, vol. 59, no. 3, pp. 200-210, 2003.

4. H. Tanino, Naevus fusco-caeruleus ophthalmomaxillaris (Ota), Jpn. J. Dermatol., 46 (1939), pp. 107-111

5. A.W. Kopf, Al. Weidman, Nevus of Ota, Arch. Dermatol., 85 (1962), pp. 195-208

6. Hidano, H. Kajima, S. Ikeda, H. Mizutani, M. Niimura, Natural history of nevus of Ota, Arch. Dermatol., 95 (1967), pp. 187-195

7. Singh AD, De Potter O, Fijal BA, Shields CL, Shields JA, Elston RC et al. Lifetime prevalence of uveal melanoma in white patients with oculodermal melanocytosis. Ophthalmology 1998; 105: 195-198.

8. Harbour JW, Brantley MA, Hollingsworth H, Gordon M. Association between choroidal pigmentation and posterior uveal melanoma in a white population. Br J Ophthalmol 2004; 88: 39-43.

9. Liu JC, Ball SF. Nevus of Ota with glaucoma: report of three cases. Ann Ophthalmol. 1991;23(8):286-9.

10. Tanino H. Über eine in Japan haufig vorkom-mende Navusform: "Naevus fusco-caeruleus ophthalmomaxillaris Ota", I. Mitteilung: Beobachtung über Lokalisation, Verfärbung, Anordnung and histologische Veränderung. Jpn J Dermatol.1939;46:435-51.

11. Consensus conference: Precursors to malignant melanoma. JAMA1984;251:1864-6.

12. Klotz S, Penn C, Negvesky G, et al. Fungal andparasitic infections2000;13:662-85. 